\title{
ANALYSIS OF THE EFFECT OF ULTRASONIC Vibrations on the Performance of Micro- Electrical Discharge MaCHINING OF A2 TOOL STEEL
}

\author{
Govindan Puthumana \\ Postdoctoral Researcher \\ Department of Mechanical Engineering, Technical University of Denmark, Lyngby.
}

\begin{abstract}
:
The application of ultrasonic vibrations to a workpiece or tool is a novel hybrid approach in microelectrical discharge machining. The advantages of this method include effective flushing out of debris, higher machining efficiency and lesser short-circuits during machining. This paper presents a systematic analysis of the influence of kinetic effects of the ultrasonic vibrations on the material removal rate (MRR) and tool electrode wear rate (TWR). The tool wear ratio was estimated for the process at all processing conditions. The maximum variation in tool wear ratio is observed to be $82 \%$. Therefore, MRR and TWR were independently analyzed by using three scientific tools: i) AOM plots, ii) interaction plots and iii) three-dimensional scatter plots. The increase in MRR is 47\% corresponding to an increase in the maximum power of vibrations by $30 \%$. The ultrasonic vibrations are found to be very effective at higher machining depths for achieving stable machining conditions. Regression equations were developed for MRR and TWR with capacitance, ultrasonic vibration factor, feed rate and machining time.
\end{abstract}

\section{KEYWORDS:}

Micro-electrical discharge machining, Ultrasonic vibration, hybrid machining, Material removal, tool electrode wear, AOM.

\section{INTRODUCTION}

In micro-electrical discharge machining, each electrical discharge generates thermal energy causing melting and evaporation of material, without any contact between the tool electrode and the workpiece. The properties of the material such as toughness, hardness and brittleness has no effect on the material removal mechanism. Because of the capability to generate complex microfeatures, the micro-EDM process has been extensively used in tool and mould making industry. Furthermore, the spark machining methods have been applied in several fields related to micromachining and prototyping [1]. The demand for micro-parts and components are increasing at a very rapid rate, and thus, the micro-EDM technology is being modified to achieve efficient machining at micro-scale [2]. One of the techniques to minimize the removal is to reduce the discharge energy. The discharge energy of the micro-EDM process is less than $100 \mu \mathrm{J}$ in a spark, and by reducing the current and pulse-on time parameters to $1 \mathrm{~A}$ and $0.2 \mu$ s respectively, a minimum discharge energy of $5 \mu \mathrm{J}$ is achievable under normal processing conditions [3]. There are few challenges to operate micro-EDM at low discharge energies; they are: 1) unstable

DOI: 10.14810/ijmech.2016.5301 
machining conditions in the inter-electrode gap due to higher number of short-circuits, 2) lower productivity and 3) geometrical inaccuracy in the features generated, and 4) poor surface finish. The number of short-circuits, arcing and abnormal discharges increases as the depth of the feature machined increases, and is a problem when the aspect ratio of the feature is high [4]. Researchers have identified concentration of debris in the spark gap as one of the key reasons, and have proposed various measures to improve the flushing out of debris and thereby to enhance the performance of the micro-EDM process, such as external jet flushing, sucking pump flushing, flushing by lifting and rotational flushing. However, due to small size of the operating region (less than $50 \mu \mathrm{m}$ ) and discharge gap (of the order of $10 \mu \mathrm{m}$ ), these conventional methods are mostly ineffective. In order to attain stable machining conditions, it is therefore necessary to use new approaches.

In ultrasonic vibration-assisted micro-EDM, a high frequency vibration of the order of $30-60 \mathrm{kHz}$ is introduced either to the tool or to the workpiece, in the range of amplitudes of 5 to $10 \mu \mathrm{m}$ [5]. The application of vibration causes significant improvements in the circulation of the dielectric and improves the gap conditions by increasing the energy of active sparks. Another effect is the pressure differences in the discharge gap, primarily because of the presence of debris particles. This facilitates relatively easy evacuation of the debris particles out of the gap [6]. Ultrasonic vibrations of $40 \mathrm{kHz}$ has been applied for drilling micro-holes of $40 \mu \mathrm{m}$, and the favorable effect was found to be a lower tool wear ratio [7]. Recently, Che et al. [8]applied ultrasonic vibrations to electrical discharge machining process and found that debris removal is equally effective for the horizontal machine tool configuration. The external application of ultrasonic vibrations is combined with abrasive jet machining [9], and with magnetic field [10]. In these new investigations on hybrid techniques, an overall improvement in productivity and better surface quality have been reported. In addition, attempts have been made to analyze the surface morphology and characterize the mechanisms of machining.

There have only been a few attempts to characterize and analyze the effects of ultrasonic vibrations on the main performance measures of micro-EDM. In one of such important investigations [11], the best combination of parameters was identified by following the signal to noise ratio approach based on Taguchi technique. Therefore, the objective of this paper is to further analyze the effect of ultrasonic vibrations on the machining performance measures such as tool electrode wear ratio, material removal rate and tool wear rate. This paper is divided into three sections. In the first section, the tool wear ratio is calculated for different processing conditions and its variation is estimated. The analysis of means method is used to analyze the MRR and TWR data in the second section. In the third section, the results of regression analysis and the developed regression equations are presented.

\section{Materials ANd Methods}

The material A2 tool steel was used for the initial experimental investigation [11] based on which this analysis is carried out. In the investigation, fine grinding was applied to finish the workpiece surfaces. The chemical composition of AISI A2 tool steel is presented in Table 1.

Table 1. Chemical composition of A2 tool steel (\%)

\begin{tabular}{|c|c|c|c|c|c|}
\hline $\mathrm{C}$ & $\mathrm{Mn}$ & $\mathrm{Cr}$ & $\mathrm{Ni}$ & $\mathrm{Mo}$ & $\mathrm{V}$ \\
\hline 1.00 & 1.00 & 5.0 & 0.3 & 1.0 & $0.15-0.50$ \\
\hline
\end{tabular}


The tool electrode of Ø200 $\mu \mathrm{m}$ was of material tungsten and was finished using wire electrical discharge grinding. The ultrasonic vibration was provided to the workpiece using a piezoelectric transducer of frequency $40 \mathrm{kHz}$ and maximum amplitude of $10 \mu \mathrm{m}$ in the vertical $\mathrm{Z}$ direction. Fig. 1 shows the principle of vibration-assisted micro-EDM.

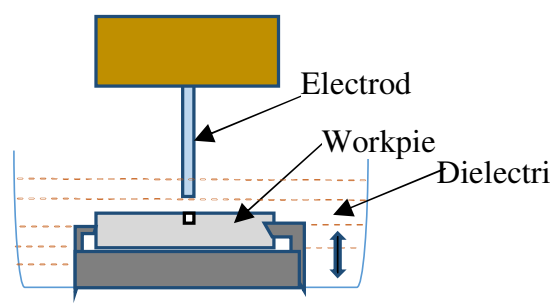

Fig. 1 A schematic of vibration-assisted micro-EDM (in the set-up: average frequency: $40 \mathrm{kHz}$, max. amplitude: $10 \mu \mathrm{m}$ )

Based on the experimental design using Taguchi L18 orthogonal array, actual experimentation [11] and measurement of material removal from the workpiece and tool, the results of MRR and TWR were obtained. The analysis using the data was done in three stages: i) analysis of tool electrode wear ratio, ii) analysis of means of MRR and TWR, and iii) regression analysis.

Table $2 \mathrm{a}-\mathrm{b}$ shows the table for originating the graphs presented in Sections 3.2 and 3.3.

\begin{tabular}{|c|c|c|c|}
\hline a. & Input conditions \\
\hline Capacitance $(\mathrm{pF})$ & 1000 & ----- & 3300 \\
\hline Percentage of peak power of vibration & 0 & 30 & 60 \\
\hline Feedrate $(\mu \mathrm{m} / \mathrm{s})$ & 1 & 3 & 5 \\
\hline
\end{tabular}

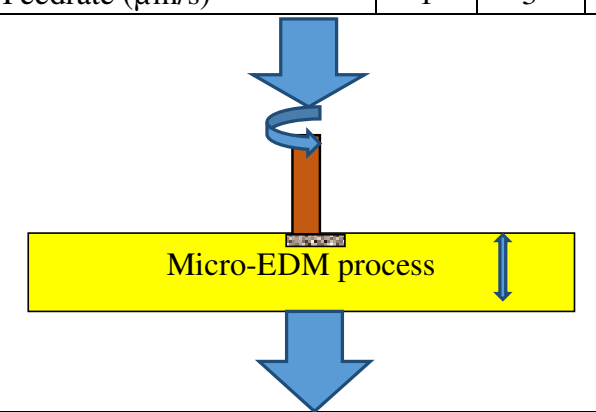

\begin{tabular}{|c|c|c|c|}
\hline \multicolumn{2}{|r|}{ b. } & \multicolumn{2}{|c|}{ Measurable process outputs } \\
\hline Trial \# & $\operatorname{MRR}\left(\mu \mathrm{m}^{3} / \mathrm{min}\right)$ & $\operatorname{TWR}\left(\mu \mathrm{m}^{3} / \mathrm{min}\right)$ & Tool wear ratio \\
\hline 1 & 500046 & 122460 & 0.244 \\
\hline 2 & 414534 & 237070 & 0.572 \\
\hline 3 & 427997 & 301440 & 0.704 \\
\hline 4 & 1165085 & 248060 & 0.213 \\
\hline 5 & 746397 & 422330 & 0.566 \\
\hline 6 & 1362570 & 254340 & 0.186 \\
\hline 7 & 905843 & 216660 & 0.239 \\
\hline 8 & 1305570 & 406107 & 0.311 \\
\hline 9 & 2057524 & 445880 & 0.217 \\
\hline 10 & 855838 & 258527 & 0.302 \\
\hline 11 & 1763868 & 364240 & 0.206 \\
\hline
\end{tabular}


International Journal of Recent advances in Mechanical Engineering (IJMECH) Vol.5, No.3, August 2016

\begin{tabular}{|c|c|c|c|}
\hline 12 & 1345486 & 422330 & 0.314 \\
\hline 13 & 975833 & 288880 & 0.296 \\
\hline 14 & 1153642 & 320280 & 0.277 \\
\hline 15 & 2444251 & 323420 & 0.132 \\
\hline 16 & 928207 & 266900 & 0.287 \\
\hline 17 & 1445989 & 185260 & 0.128 \\
\hline 18 & 1222457 & 430180 & 0.352 \\
\hline
\end{tabular}

Table 2 a-b The input conditions (a) and measurable process outputs (b) for analysis, the outputs presented

\section{RESULTS AND DISCUSSION} calculated based on [11] used for detailed analysis

\subsection{ToOl Electrode Wear Ratio}

The calculated values of tool electrode wear ratio is presented in Fig. 2. The maximum tool wear ratio for the investigation was 0.704 for the third trial,while the minimum was 0.128 for the seventeenth trial. Hence, the extreme variation in the tool wear ratio for the investigation is found to be $82 \%$. The average value of tool wear ratio for the investigation is 0.308 . The differences in the magnitudes of tool electrode wear ratio indicates the variations in MRR and TWR, because of the complexity of the physics of micro-EDM process. Therefore, a systematic analysis of means is performed on the MRR and TWR data.

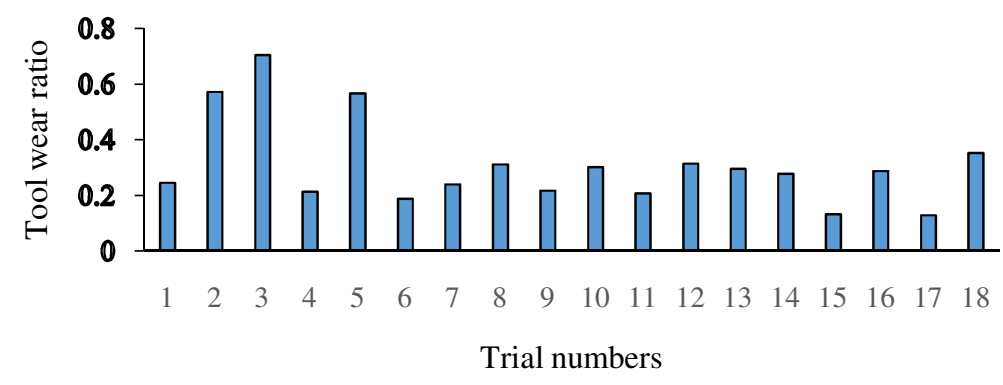

Fig. 2 The variation of tool electrode wear ratio in micro-EDM

\subsection{Analysis Of Means OF MRR}

The main effects of the processing conditions on the MRR is evaluated in ultrasonic-vibration assisted micro-EDM process. Fig. 3 a-d shows the AOM plots of MRR with capacitance (a), percentage of peak power vibration (b), feed rate (c) and machining time (d). Though the effects occur simultaneously during the spark machining, each effect is considered individually. 


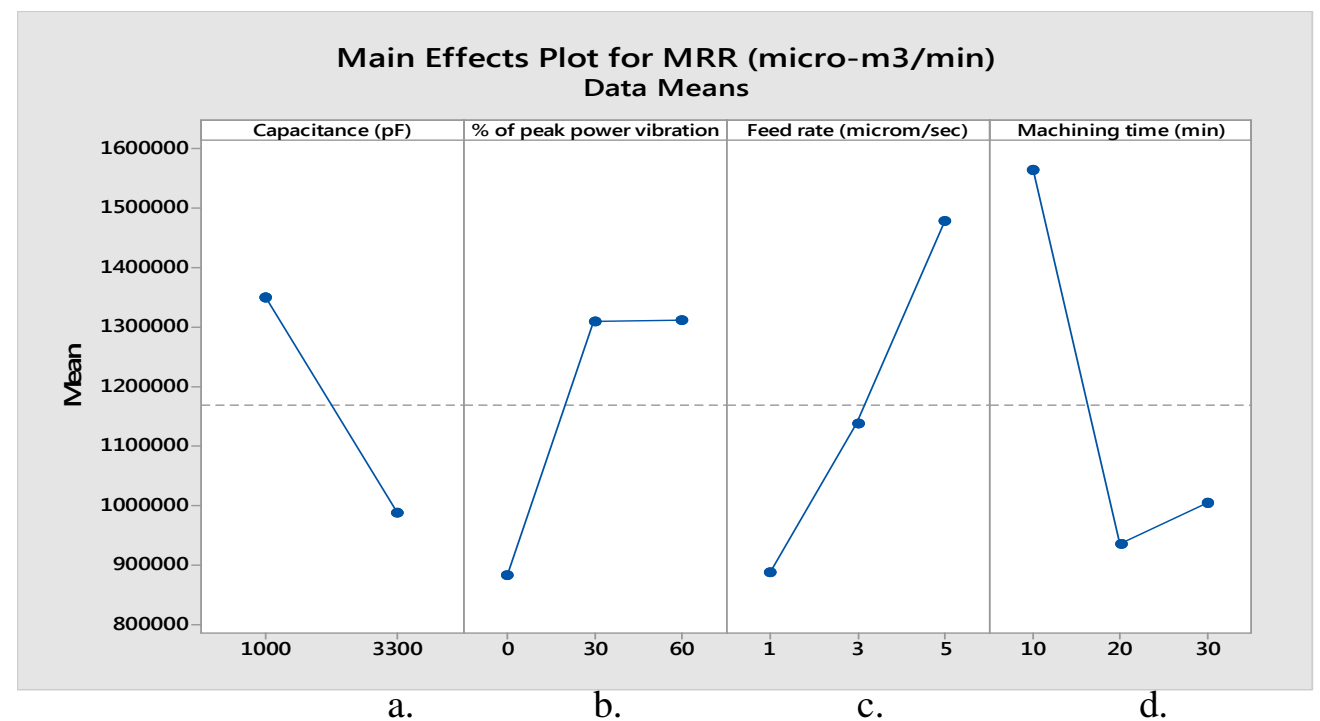

Fig. 3 a-d The AOM plots of MRR with the input factors

The capacitance (first factor) has only two levels in the $\mathrm{L}_{18}$ experimental design because its variations are taken into account in the first column of the table [11]. As seen from Fig. 3-a, the MRR decreases linearly with an increase in the capacitance. Normally, the discharge energy varies linearly with the capacitance, and thus a linear increase in MRR is expected. However, in some machining circumstances, when the feed rates are very small, most of the time is utilized for movement of the tool electrode [12].

The AOM plot presented in Fig. 3-b shows that an increase in MRR is observed with an increase in percentage of the power of ultrasonic vibrations. As the percentage of peak power of vibrations increases from 0 to 30, the increase in MRR is seen to be $47 \%$. The kinetic energy in the ultrasonic vibrations helps reduce short-circuiting, reduce the number of inactive pulses and removal of the debris particles from the discharge gap. However, with a further increase in peak power, the rate of increase in MRR is decreased. This could be because of the heating effect at higher levels of ultrasonic power, see Ref. [13].

The material removal rate increases linearly with an increase in the feed rate, see Fig. 3-c. The MRR increases by $70 \%$ by the influence of federate. The feed rate causes an increase in the action of flushing out the debris particles from the discharge gap, which has a positive effect on the material removal [14]. The effect is further enhanced by the introduction of ultrasonic vibrations. Considering the factor machining time, effect of its increase is to decrease the MRR, see Fig. 3-d. With an increase in machining time, the depth of the cavity also increases. The agglomeration of debris particles makes it very difficult to achieve stable sparking conditions. The external application of ultrasonic vibrations are effective to some extent [15]. As can be seen from Fig. 3-d, with an increase in machining time from 20 to $30 \mathrm{~min}$, an increase in MRR by 7\% is achieved, which could be attributed to the effect of ultrasonic vibrations.

The interactions among the factors are considered for analysis and the interaction plots are presented in Fig. 4. The total number of interactions are 6 and are: capacitance $\times$ percentage of peak power of vibration, capacitance $\times$ federate, capacitance $\times$ machining time, percentage of 
peak power of vibration $\times$ federate, percentage of peak power of vibration $\times$ machining time and federate $\times$ machining time. It is observed that when the factors interact, no specific favorable effects are observed. In the interaction plot capacitance $\times$ federate, an overall increase in MRR is observed. This could be attributed to the effect of ultrasonic vibrations to minimize arcing and short-circuiting, effect of capacitance to concentrate higher discharge energy and the effect of federate to increase the rate of machining. Fig. 5 a-d shows the three-dimensional scatter plots of MRR with all the factors.

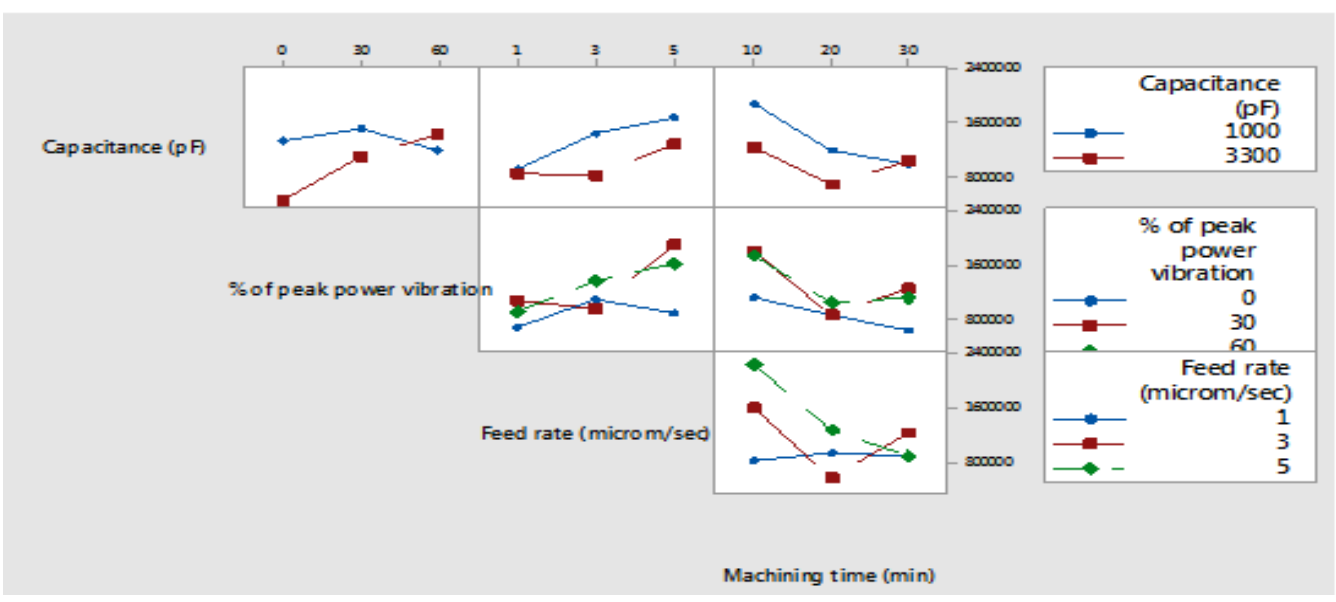

Fig. 4 Interaction plots for MRR

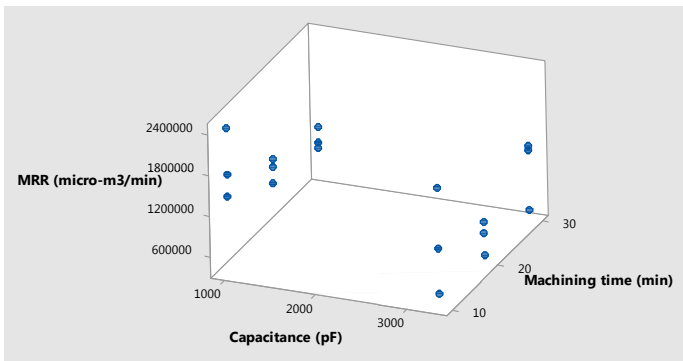

a.

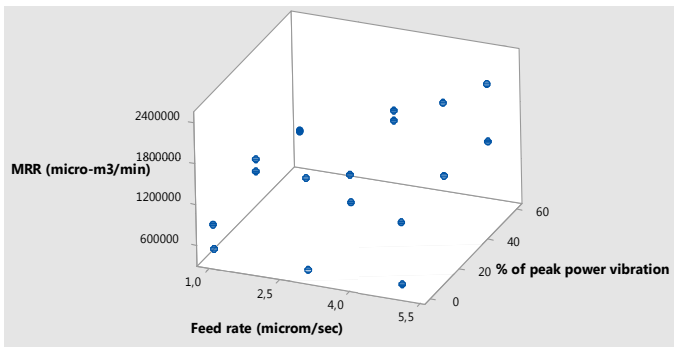

b. 
International Journal of Recent advances in Mechanical Engineering (IJMECH) Vol.5, No.3, August 2016

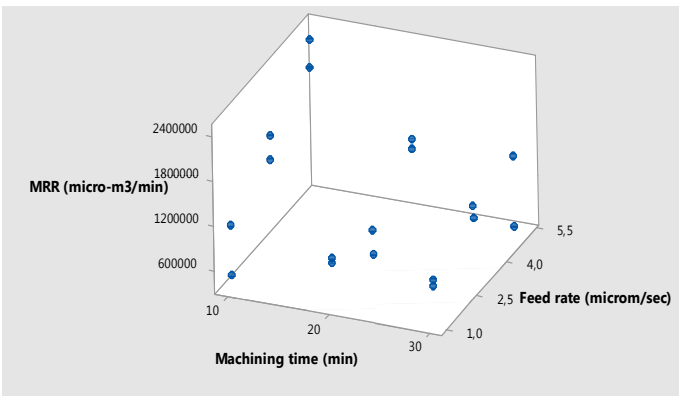

c.

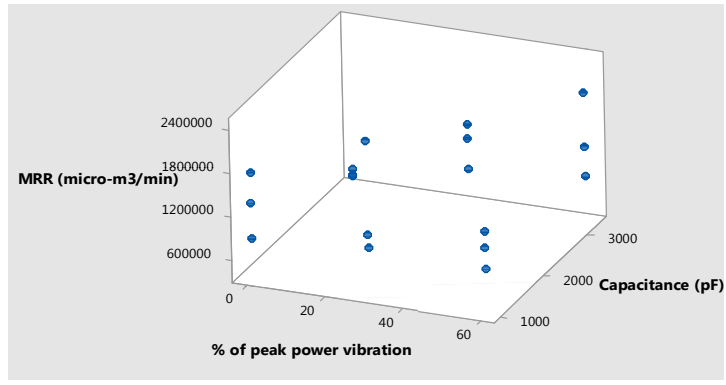

d.

Fig. 5 a-d The three-dimensional scatter plots for MRR with the controllable factors

\subsection{ANALYSIS OF MEANS OF TWR}

The effect of ultrasonic vibrations on the removal of material from the tool electrode is analyzed using AOM plots for TWR. The results of analysis of means are presented in Fig. 6 a-d.

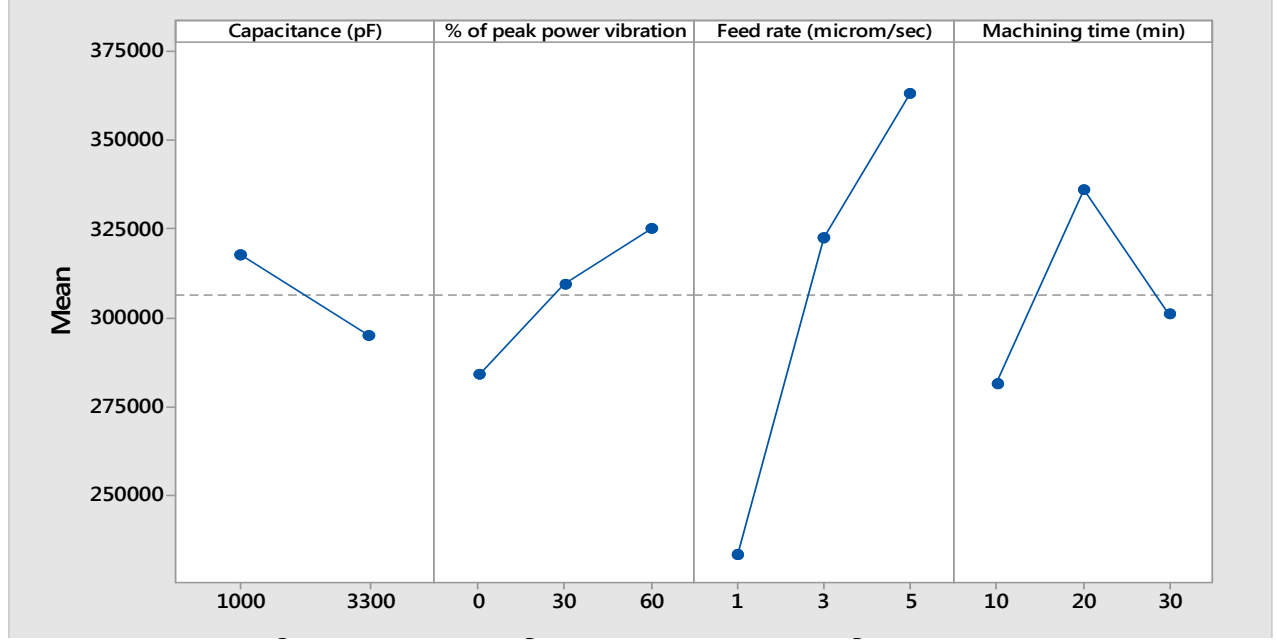

The effect of capacitance on TWR is similar to that for MRR. A reduced transfer of discharge energy to the tool electrode causes a decrease in the tool wear rate too (Fig. 6-a). The effect of 
ultrasonic vibration is to increase the tool wear rate. The effect is predominant at higher power of peak vibration. This could be because of the effect of additional heating generated from the vibrations (see Fig. 6-b). As the federate increases, the tool wear rate also increases significantly (Fig. 6-c). This could be because of an increase in the frequency of interaction of the tool electrode surface with the plasma channel. It can be observed from Fig. 6-d that an increase in machining time from 20 to 30 min causes a decrease in the tool electrode wear. This effect could be attributed to the effect of ultrasonic vibrations to flush out workpiece material without consuming the tool electrode material. Fig. 7 shows the interaction plots for TWR. Three dimensional scatter plots for TWR with all the controllable factors is presented in Fig. 8 a-d.

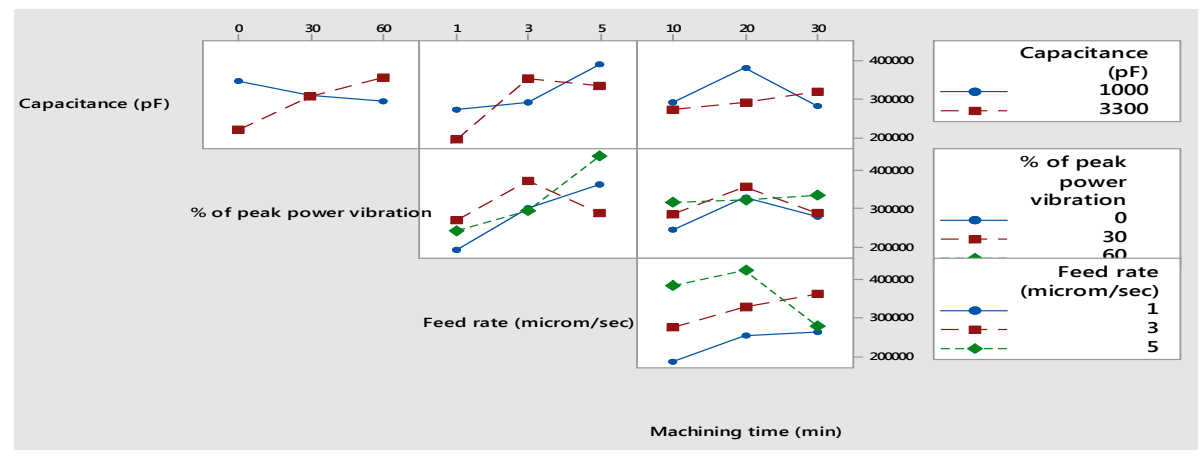

Fig. 7 Interaction plots for TWR

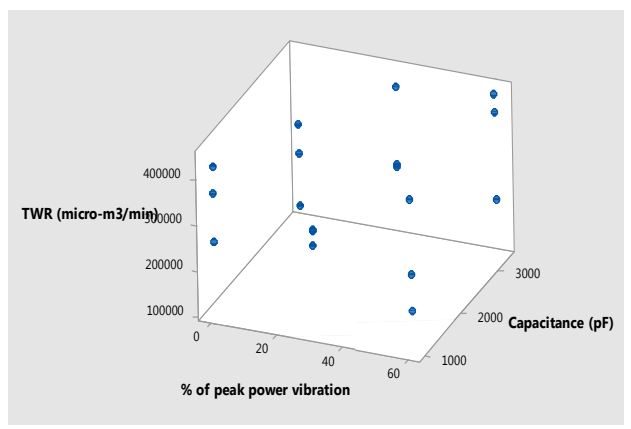

a.

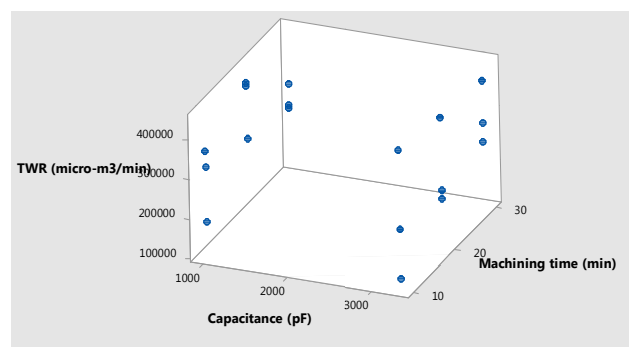

c.

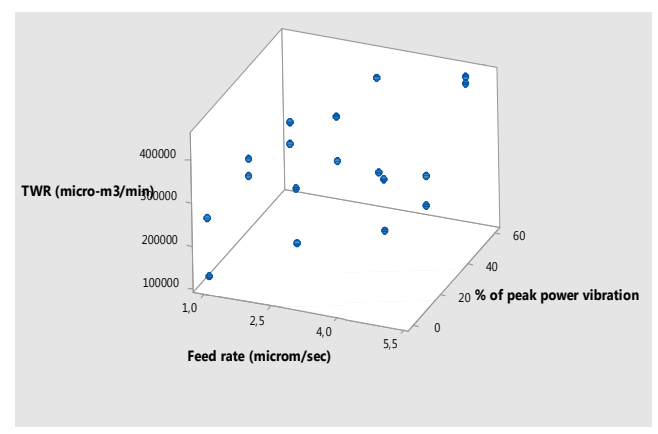

b.

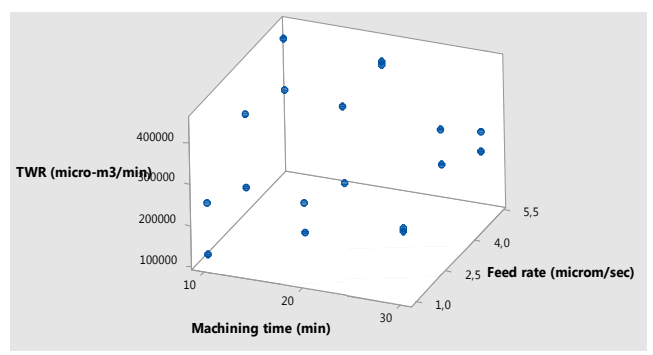

d.

Fig. 8 a-d Three-dimensional scatter plots for TWR with the controllable factors 


\subsection{REgRESSION ANALYSIS OF MRR AND TWR}

Regression analysis method is used to determine the mathematical relationship between the process outputs and the input factors. The regression equation for MRR is obtained as:

$M R R=1408227-157.0 \times C+7105 \times P+147060 \times f-27858 \times T_{m}$

where, $C$ is the capacitance in $\mathrm{pF}, P$ is in percentage $(\%), f$ is the federate in $\mu \mathrm{m} / \mathrm{s}$ and $T_{m}$ is the machining time in minutes.

$$
\mathrm{S}=376455, \mathrm{R}-\mathrm{sq}=62.73 \%
$$

The residual plots for MRR are presented in Fig. 9.

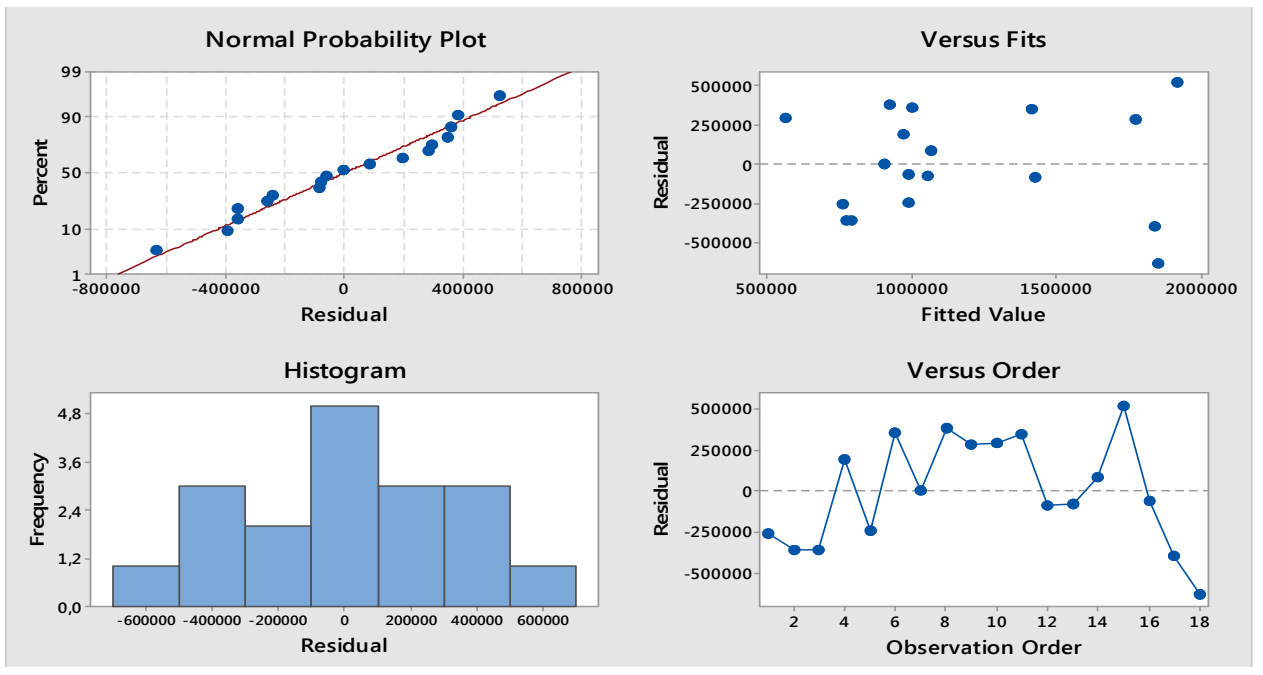

Fig. 9 Residual plots for MRR

Regression analysis was performed on the TWR data, and the expression is:

$T W R=190580-9.9 \times C+680 \times P+32338 \times f+986 \times T_{m}$

$\mathrm{S}=82453.7, \mathrm{R}-\mathrm{sq}=39.91 \%$ 


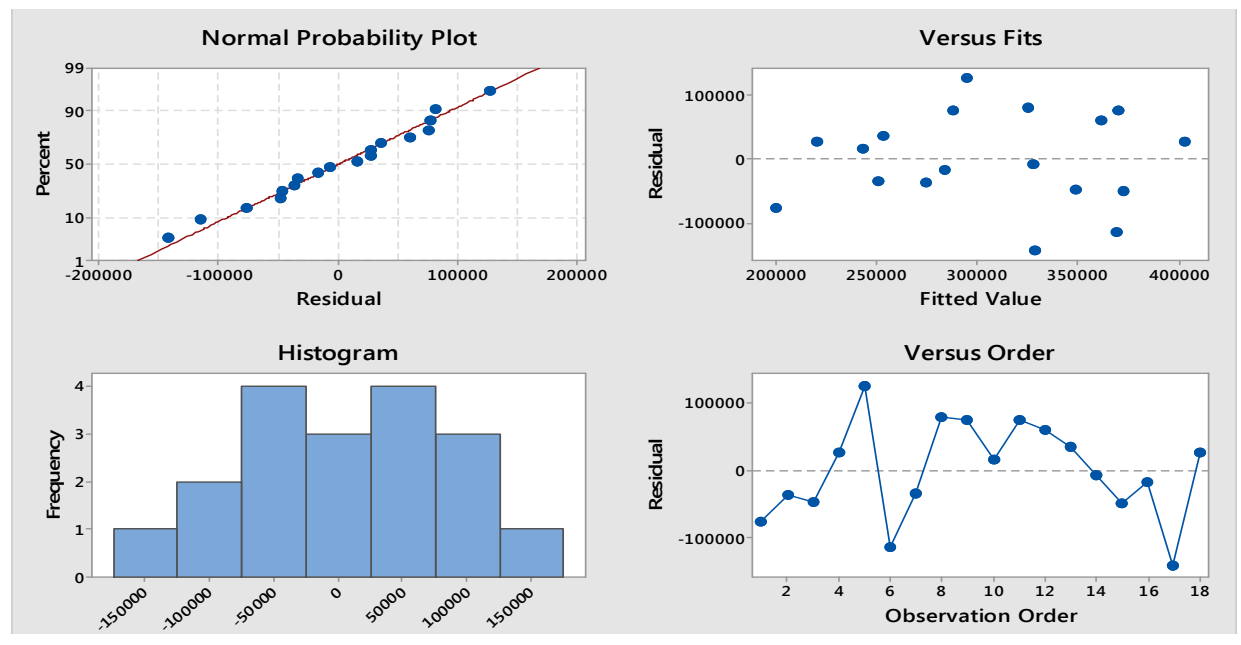

Fig. 10 shows the residual plots for TWR.

\section{CONCLUSIONS}

The effect of ultrasonic vibrations on the performance of micro-EDM in machining A2 tool steel is systematically analyzed and presented in this paper. The main favorable effect of ultrasonic vibrations is to effectively evacuate debris from the discharge gap even at higher machining depths. As a result, an increase in MRR and, at the same time, a decrease in TWR could be observed at higher machining depths. The effects of capacitance, percentage of peak ultrasonic vibrations, federate and machining time on MRR and TWR have been analyzed. Based on this work, the following conclusions can be derived:

- The tool wear ratio for the process was calculated at various processing conditions. A maximum variation in the tool wear ratio of $82 \%$ was observed in the process for the selected processing conditions. This could be because of the larger range of parameters chosen for the investigation.

- An increase in MRR is observed with an increase in percentage of the power of ultrasonic vibrations. As the percentage of peak power of vibrations increases from 0 to $30 \%$, the increase in MRR is seen to be $47 \%$. The kinetic energy in the ultrasonic vibrations helps reduce short-circuiting, reduce the number of inactive pulses and removal of the debris particles from the discharge gap.

- The effect of ultrasonic vibration is to increase the tool wear rate. As the percentage of peak power of vibrations increases from 0 to $60 \%$, an increase in TWR is observed to be $18 \%$. The effect is predominant at higher power of peak vibration. This could be because of the effect of additional heating generated from the vibrations

- With an increase in machining time from 20 to $30 \mathrm{~min}$, an increase in MRR by $7 \%$ is achieved, which could be attributed to the effect of ultrasonic vibrations. At lower depths of machining, the mechanism of flushing out the eroded particles with the jet of liquid 
dielectric is not effective. The ultrasonic vibrations transfers the kinetic energy to the debris particles and helps flush the particles out.

- An increase in machining time from 20 to 30 min causes a decrease in the tool electrode wear. This effect could be attributed to the effect of ultrasonic vibrations to flush out workpiece material without consuming the tool electrode material.

- Regression equations were developed for MRR and TWR, by considering the effect of all the input factors.

\section{ACKNOWLEDGEMENTS}

The author would like to acknowledge the support from H.C. Ørsted COFUND postdoc fellowship.

\section{REFERENCES}

[1] Kunieda, M., Lauwers, B., Rajurkar, K. P. and Schumaker, B. M. (2005), Advancing EDM through Fundamental Insight into the Process, CIRP Annals-Manufacturing Technology, v54, n2, pp. 64-87.

[2] Rajurkar, K. P., Levy, G., Malshe, A., Sundaram, M. M., McGeough, J., Hu, X., Resnick, R. and DeSilva, A. (2006), Micro and Nano Machining by Electro-Physical and Chemical Processes, v55, n2, pp. 643-666.

[3] Uhlmann, E., Piltz, S. and Doll, U. (2005), Machining of micro/miniature dies and moulds by electrical discharge machining-Recent development, Journal of Materials Processing Technology, v167, n2-3, pp.488-493.

[4] Liao, Y.S., Chang, T.Y., Chuang, T.J. (2008),Anon-line monitoring system for a micro electrical discharge machining (micro-EDM) process. Journal ofMicromechanics and Microengineering, v18, n3, 035009.

[5] Garn, R., Schubert, A. Zeidler, H. (2011), Analysisof the effect of vibrations on the micro-EDM process at the workpiece surface. Precision Engineering, v35, n2, pp. 364-368.

[6] Yeo, S.H., Tan, L.K. (1999), Effects of ultrasonicvibrations in micro electro-discharge machining ofmicroholes. Journal of Micromechanics and Microengineering, v9, n4, pp. 345-352.

[7] Ichikava, T. and Natsu, W. (2013), Realization of micro-EDM under ultra-small discharge energy by applying ultrasonic vibration to machining fluid, The Seventeenth CIRP Conference on Electro Physical and Chemical Machining (ISEM), pp. 326-331.

[8] Che, J., Zhou, T., Zhu, X., Kong, W., Wang, Z. and Xie, X. (2016), Experimental study on horizontal ultrasonic electric discharge machining, Journal of Materials Processing Technology, v231, n1, pp. 312 318.

[9] Lin, Y., Hung, J., Chow, H., Wang, A., Chen, J. (2016), Machining Characteristics of a Hybrid Process of EDM in Gas Combined with Ultrasonic Vibration and AJM, 18th CIRP Conference on Electro Physical and Chemical Machining (ISEM XVIII), v42, n1, pp. 167-172.

[10] Zhang, Z., Huang, H., Ming, W., Xu, Z., Huang, Y., Zhang, G. (2016), Study on machiningcharacteristics of WEDM with ultrasonic vibration and magnetic field assisted techniques, v234, n1, pp. 342-352.

[11] Sundaram, M. M., Pavalarajan, G. and Rajurkar, K. P. (2007), A Study on Process Parameters of Ultrasonic AssistedMicro EDM Based on Taguchi Method, v17, n2, pp. 210-215.

[12] Yu, Z., Rajurkar, K. P. and Prabhuram, P. D. (2001), Study of contouring micr-EDM characteristics, Initiatives of Precision Engineering at the beginning of a millennium, 10th International Conference on Precision Engineering (ICPE), July 18-20, 2001, Yokohama, Japan, pp. 199-203.

[13] Oh, Y.K., Park, S. H. and Cho, Y. I. (2002), A study of the effect of ultrasonic vibrations on phase-change heat transfer, v45, n23, pp. 4631-4641.

[14] Sivaprakasam, P., Hariharan, P. and Gowri, S. (2014), Modeling and analysis of micro-WEDM process of titanium alloy (Ti-6Al-4V) using response surface approach, v17, n4, pp. 227-235.

[15] Liao, Y. S. and Liang, H. W. (2016), Study of Vibration Assisted Inclined feed Micro-EDM Drilling, 18th CIRP Conference on Electro Physical and Chemical Machining (ISEM XVIII), pp. 552-556. 